\title{
Day Care Subsidy for the Child at Home A Finnish Experiment
}

\section{ANNIKKI SUVIRANTA}

Director

\section{RIITTA SÄNTTI}

Research Associate

The Research Institute of Ministry of Social Affairs and Health

As a consequence of changes in Finnish society during the 1960's and the 1970 's, the question of the day care of children has become very topical. The following statistical indicators illustrate these societal changes:

- the portion of the labour force engaged in agriculture and forestry has decreased from $36 \%$ in 1960 to $12 \%$ in 1979 ,

- the corresponding portion for the service sector has increased from 34 in 1960 to $54 \%$ in 1979 ,

- the portion of the population living in the cities has increased from $38 \%$ in 1960 to $60 \%$ in 1980 ,

- in 1980, $55 \%$ of all university level students were women, and

- the portion of women who have entered the labour market increased from $41 \%$ in 1960 to $53 \%$ in 1975.

The high educational level of Finnish women is a motivating factor for them to enter the labour market. The supply of day care facilities, however, has not met the demand. As a consequence, young couples choose not to have children, or at least no more than one or two children. At the beginning of the 1970's the birth rate in Finland was one of the lowest ones in Europe. Population predictions showed a decrease in the population of the country.

In Finland, the municipalities take care of the arrangement of the day care of children. Only about one fourth of all pre-school aged children can be taken into state-subsidized day care, as represented by day care nurseries and organized children's day care in families. As a consequence, it has been suggested that the day care of children at home be subsidized in order for families to have a greater range of alternatives in arranging the day care of their children.

\section{The experiment and the goals}

In Finland, "maternity pay" as a family policy subsidy form received increasing attention during the 1960 's. In this, the term »subsidized care at home» referred to the social welfare assistance or increased child allowances 
to be paid to mothers taking care of young children. The recipient was expected to remain at home in order to take care of her children. Already during the 1960 's, a few municipalities took the initiative in providing maternity pay to mothers taking care of children at home.

In April of 1977, the Ministry of Social Affairs and Health appointed an executive working group for an experiment with various ways of subsidizing the day care of children at home. The executive working group was assigned the task of drafting a detailed plan for the arrangement of the experiment in accordance with the instructions of the Ministry, and of proposing which municipalities would participate in the experiment. In addition, the executive working group was to draw up drafts for agreements between these municipalities and the state on the arrangement of the experiment. On September 14, 1977, a Council of State decision was given on the guidelines for state subsidies for experiments with the subsidized day care of children. On the same day, the Council of State approved the plan for such an experiment. According to the Council of State decision, the subsidization of the day care of children refers to the economic support which municipalities provide to the guardian of a child, when the purpose of this support is to promote the care and raising of young children at home after the maternity allowance provided for by the national health insurance scheme is no longer paid. The experiment with subsidized day care of children lasted from the beginning of 1978 to the end of 1980 .

The purpose of the experiment with the subsidized day care of children, according to the Council of State decision, was to answer among others the question of how different experimental alternatives affected family circumstances, the care and raising of children and the choice of the form of care. The experiment was designed to show what types of families chose the various experimental alternatives, to what extent the experiment met the expectations of the parents, and how the experiment affected the social and financial situation of the family. Interest was to be paid to the breakdown of the financial and administrative costs of subsidized day care in each alternative. Furthermore, the study was designed to clarify the right of the parent to maintain her employment relationship and her social benefits as well as her right to return to her previous place of employment after she no longer received subsidies for day care. In this, attention was paid to the necessity of developing the general rights of employees against being given notice, using as a point of departure the needs demonstrated in the experiment. Finally, the experiment was designed to ascertain the suitability of subsidized day care for families with several young children, chronically ill or handicapped children cared for at home, or other family members cared for at home in addition to young children.

\section{The experimental alternatives}

Day care subsidies were paid from the month when the payment of the maternity allowance ceased to the end of the month during which the child 
reached the age of two years or fifteen months, depending on the alternative. Maternity leave in Finland, after May 1, 1980, lasted about 9 months (210 workdays). ${ }^{1}$ The maternity leave begun about one month before the expected delivery. During maternity leave, mothers received the daily allowance provided for in the National Health Insurance Act. A prerequisite for receiving subsidized day care was that the child was cared for at home. If the children in the family participated in organized day care activity or supervised play and recreation for child welfare purposes, however, this in itself does not bared the family from receiving subsidized day care. The experiment provided the following three alternatives for subsidized day care:

\section{Experimental alternative $I$}

In experimental alternative I subsidized day care was based on case-bycase discretion. A prerequisite for receiving this subsidy form was the family's need for financial support or other special family circumstances. The size of the subsidy was calculated on the basis of the difference between the family's available income and the family's expenditure, calculated according to a certain formula.

This experimental alternative required that the child was cared for at home, but it needed not be the parents who took care of the child. In this alternative, the subsidy was granted up to the end of the month during which the child reached the age of two years.

\section{Experimental alternative II}

In experimental alternative II, a requirement for receiving the subsidy was that one of the parents cared for the child at home. The parent leaving work outside of the home in order to take over caring for the child at home was not allowed to receive any pay or any form of benefit in lieu of pay, nor was the family allowed to rely on communal or any other day care services. Participation of the children in organized day care activity or supervised play and recreation for child welfare purposes, however, did not bar the family from receiving subsidized day care. The prerequisites for the granting of a subsidy could be relaxed in regard to the restriction on going to work or receiving any benefit in lieu of pay or the use of other child day care services in the case of lone parents and those with limited means.

At the beginning of the experiment, day care subsidies were paid in equal amounts to all families regardless of the number of children in the family. The size of the subsidy in this alternative was 400 marks a month. ${ }^{2}$ The subsidy was increased to 450 marks per month on June 1, 1979. In addition, 225 marks per month were paid for each other child in the family under the age of 3 . The subsidy was paid to the end of the month during which the child reached the age of two years.

1 . From the 1st of July 1981, 258 workdays.

21 USD $=4.55$ Marks (July 1981). 


\section{Experimental alternative III}

In experimental alternative III, the size of the subsidy was based on the income of the parent choosing to remain at home, using as a basis the formula for calculating the daily allowance according to the national health insurance scheme. The minimum daily allowance was 500 marks a month. The greater the income of the parent, the larger the allowance. The maximum was 1430 marks a month. One of the parents had to remain at home to care for the child. When the experiment began in 1978, a prerequisite in this alternative was that, in addition to one child under the age of one, the family had at least one preschool aged child or one handicapped, ill or elderly person to care for. If the child in question was handicapped or ill, however, a subsidy could be granted even to one-child families. The general subsidy conditions could also be relaxed in the case of families in especially difficult circumstances. Such difficult circumstances were lone parent families, shift work, awkward working hours and work-related travel. The requirement that the family has two pre-school aged children was removed on June 1, 1979.

At the beginning of the experiment, day care subsidies were paid to the end of the month during which the child reached the age of one year. From June 1, 1979 on, the subsidy could be paid to the end of the month during which the child reached the age of fifteen months.

\section{The extent of the experiment}

The municipalities participating in the experiment had been selected so that they represented different industrial, population and urbanization structures as well as different parts of the country. The participating municipalities had been assigned among the three experimental alternatives so that as far as possible the results could be generalized nation-wide.

A total of 21 municipalities were participating in the experiment. Families with a child born on or after July 1, 1977 were eligible for participation in the experiment. Parents with children in the municipalities in question had been informed of the experiment, and requests for subsidies were to be directed to the municipal social welfare board.

When the experiment began in 1978 , each municipality was assigned a child quota, establishing the limits on the number of participating families in the municipality. For this reason, it was not possible for all families fulfilling the eligibility criteria to receive subsidies. This was especially true of experimental alternatives II and III. In alternative I, on the other hand, the municipal quotas were not always met, as already the basis for granting subsidies in itself affected the number of families receiving subsidies. The state removed these child quotas from June 1,1979 on. It was not possible for all of the municipalities to abandon these quotas during 1979 , however, as the quotas had formed 
the basis for the allotment of funds for the experiment in the 1979 annual budget. In many municipalities, the quotas were not removed until the beginning of 1980 .

\section{The costs of the experiment}

Municipalities participating in the experiment could receive a $50 \%$ rebate from the state on the total amount of day care subsidies granted. The municipalities had agreed to finance all of the costs of the experiment in excess of the share borne by the state. In 1978, the total expenditure for the experiment was 2.4 million marks; in 1979 , it was 4.1 million marks.

\section{The families participating in the experiment}

In 1978, 744 families received subsidized day care. In 1979, the corresponding figure was 1385 families.

The average size of the day care subsidy in 1979 in the different experimental alternatives was as follows: alternative I, 493 marks a month; alternative II, 455 marks a month and alternative III, 733 marks a month.

The parent choosing to stay at home to care for the child once the maternity allowance period ends was, in $97 \%$ of the families, the mother, in $2 \%$ the father and in $1 \%$ someone else. The average age of the parents receiving the subsidy was quite young. The mothers' average age was 27.2 years; the fathers'; 29.9 years. Of the participating families, $29 \%$ had one child, $62 \%$ two or three children and $9 \%$ four or more children. The socioeconomic breakdown of these families was as follows: upper administrative and clerical employees $12 \%$, lower administrative and clerical employees $18 \%$, other employees $51 \%$, entrepreneurs $17 \%$ and students $2 \%$. Before the maternity leave, $45 \%$ of the mothers had worked outside of the home, $35 \%$ had worked at home without pay, $10 \%$ had been an entrepreneur or an assisting family member, $4 \%$ had received unemployment benefits and $6 \%$ had been studying or had had temporary work. Of the mothers in the participating families, $37 \%$ had no vocational training, $29 \%$ had completed a vocational training course, $30 \%$ had a school or institute level certificate, and $4 \%$ had a university degree.

\section{Reasons for the termination of the day care subsidies}

During 1978 and 1979 , payment of subsidies to 917 families was terminated. In about one third of these cases, payment was interrupted in advance of the normal time. In alternative I, based on case-by-case discretion, payment was terminated in $59 \%$ of the cases. This is a considerably higher figure than is 
the case with the other alternatives: in alternative II, the corresponding figure was $35 \%$ and in alternative III, $14 \%$. The most common reason for the interruption of payment was the entry of the mother into the labour market. The mother had to go to work in the middle of the day care subsidy period either for financial reasons or in order to retain her employment. The second most common reason for the termination of payments was changes in the family's financial situation. This was especially true of the families participating in alternative I, where the size of the subsidy depended on the family income. The third most common reason was that the family in question moved to a municipality where it was not possible to receive subsidized day care. The small size of the subsidy was indicated by $4 \%$ of the families as the reason for withdrawing from the experiment. Other reasons for the termination of payment were the sending of the children to care outside of the home due to the mother's illness or studies, and the fact that the mother returned to her studies.

\section{Duration of the day care subsidy payment}

Families for whom the payment of day care subsidies was terminated during 1978 and 1979 were eligible for the subsidy beginning with the month that the payment of the maternity allowance ceases, to the end of the month during which the child reaches the age of two years (alternatives I and II) or one year (alternative III).

The average length that the families for whom payment of the subsidy was terminated received the subsidy was 12.2 months in alternative I, 12.0 months in alternative II and 6.1 months in alternative III. In alternatives I and II, the families had a theoretical possibility of receiving day care subsidies for 1719 months, and in alternative III, for $6-7$ months. One of the reasons that the average length of the payment of the subsidy was shorter than expected in alternative I was the large number of families withdrawing from the experiment, while one of the reasons in alternative II was that after the quotas were removed, subsidies were paid to families who could only receive them for a few months more.

\section{Employment after the termination of payment}

After the termination of the period of subsidy payment, $49 \%$ of the parents who had taken care of their child at home - primarily the mothers - remained at home to work without pay, $41 \%$ went to work outside of the home, $5 \%$ became an entrepreneur or an assisting family member, $2 \%$ took in other children for care at home, and $3 \%$ pursued studies or took temporary work. 
In comparing the rate of going to work after the termination of the period of subsidy payment with the rate that mothers worked before the birth of their child, it could be seen that in all the alternatives, participation in the labour market became less common. Before the birth of their child, $45 \%$ of the mothers had worked outside of the home, but after the termination of the period, $41 \%$ of the mothers worked outside of the home. The portion of mothers engaged in work at home without pay increased from $35 \%$ to $49 \%$.

\section{The opinions of the families}

After the termination of the period of subsidy payment, the participating families were asked whether or not the day care subsidy had met the family's expectations. In alternative I, $38 \%$ of the families were of the opinion that the subsidy did not come up to their expectations. In the other alternatives, the portion of the families dissatisfied with the subsidy was smaller: $18 \%$ in alternative II and $13 \%$ in alternative III. In alternative I, dissatisfaction was directed primarily at the small size of the subsidy. Other reasons for dissatisfaction were the basis on which the subsidy was granted, the fact that the period of leave of office terminated in the middle of the day care subsidy period, and the briefness of the subsidy period. In alternative II, dissatisfaction was caused both by the small size of the subsidy and the briefness of the subsidy period. In alternative III, the largest source of dissatisfaction was the briefness of the subsidy period.

The participating families for whom payment was terminated were also asked their opinion of subsidized day care. No attempt was made to limit the response alternatives; the families were allowed to give their answers freely. $65 \%$ of the families indicated that they regarded subsidized day care as worthwhile. It is probable that even more of the families took a positive attitude towards the matter, as not all of the families bothered to answer this openended question. The criticism expressed by the families answering this question was much the same as the reasons for dissatisfaction expressed by those dissatisfied with the subsidy: criticism was directed primarily against the small size of the subsidy and the briefness of the subsidy period. In alternative I, $26 \%$ of the families regarded the subsidy as too small, and $8 \%$ felt that the period was too brief. In alternative II, criticism was directed equally at the small size of the subsidy and the briefness of the period (16\%). In alternative III, $26 \%$ of the families regarded the subsidy period as too brief and only $6 \%$ felt that the subsidy was too small. The criticism expressed by the families could be regarded as quite natural: in alternative I, many families received a rather small subsidy up to the time the child was two, while in alternative III, the families received a rather large subsidy but only up to the time the child reached the age of one year. 
The State budget for 1980 included the sum of 25 million marks (and for 198160 million marks) for supporting the care of children in their own home. The results of the experiment on day care subsidy were used in deciding how this sum reserved for the support of home care was to be divided. This support, which is paid to families with many children, is 700 marks per month. The subsidy is now paid from the beginning of the month when the maternity allowance mentioned in the health insurance law ends until the end of the month in which the child reaches the age of three years. In order to be eligible for receiving this support, there must be three children under school age in the family, and one of them must be under three years of age. The child making the family eligible for this payment may not participate in government-funded day care services. 